\title{
Caraway Oil
}

National Cancer Institute

\section{Source}

National Cancer Institute. Caraway Oil. NCI Thesaurus. Code C107278.

The oil pressed from the seed fruits of Carum carvi. Caraway oil is used as a fragrance component. 